\title{
Seleção de diretores e o sentido da gestão escolar: percepções de diretores sobre o plano de gestão
}

\section{Selection of school principals and the meaning of school management: principals' perceptions about the management plan}

\author{
Maria de Fátima Magalhães de Lima*
}

\begin{abstract}
RESUMO
Nas redes públicas de ensino do Brasil tem se estabelecido crescentemente mecanismos mistos de seleção de diretores escolares, no sentido de aferir a competência técnica e política dos candidatos para gerir as escolas. No contexto do processo de descentralização de políticas educacionais e afirmação do paradigma pós-burocrático de matriz gerencial, o plano de gestão, requisito técnico para a seleção dos diretores, constitui-se como instrumento para indução do uso de indicadores educacionais, definição de metas e alcance da eficácia escolar. Com base em análise bibliográfica, documental e entrevistas semiestruturadas, este estudo de caso busca verificar as percepções dos diretores de duas escolas da rede pública municipal do Rio de Janeiro, considerados burocratas do nível de rua, sobre a implementação da diagnose e autoavaliação, etapas constitutivas do plano de gestão nas escolas. Verificamos que as diretoras participantes da pesquisa atuaram com margens de liberdade para gerir o processo, e que baseadas nas distintas experiências e valores atribuíram sentidos diferentes aos planos de gestão.

Palavras-chave: Diretores escolares. Gestão escolar. Plano de gestão. Implementação de política educacional. Burocrata do nível de rua.
\end{abstract}

* Ministério Público do Estado do Rio de Janeiro. Centro de Apoio Operacional das Promotorias de Justiça de Tutela Coletiva de Proteção à Educação. Rio de Janeiro, Rio de Janeiro, Brasil. E-mail: 13fatimamlima@gmail.com - http://orcid.org/0000-0002-7829-8383 


\begin{abstract}
Mixed mechanisms for selecting school principals have been increasingly established in public education systems in Brazil in order to assess the technical and political competence of candidates to manage schools. In the context of the process of decentralizing educational policies and affirming the post-bureaucratic paradigm of the management matrix, the management plan, a technical requirement for selecting principals, is an instrument to induce the use of educational indicators, the definition of goals and the achievement of school effectiveness. Based on bibliographic and documentary analysis and semi-structured interviews, this case study seeks to verify the perceptions of the principals of two public schools in Rio de Janeiro, considering them as street-level bureaucrats, regarding the implementation of diagnosis and self-evaluation, which are constitutive stages of the management plan in schools. We found that the principals who took part in the study acted with margins of freedom to manage the process and, based on different experiences and values, they attributed different meanings to the management plans.
\end{abstract}

Keywords: School principals. School management. Management plan. Educational policy implementation. Street-level bureaucrat.

\title{
Introdução
}

Este estudo, realizado com base em pesquisa bibliográfica, documental e entrevistas semiestruturadas, analisa as percepções de diretores escolares sobre a construção do plano de gestão, previsto para ser construído com as comunidades escolares nos três primeiros meses do mandato, após a homologação do resultado do processo misto/híbrido de seleção de diretores, adotado desde a década de 1990 na rede pública municipal de ensino do Rio de Janeiro.

Esse processo de seleção foi institucionalizado recentemente no país, por meio da Meta 19 do Plano Nacional de Educação, sancionado pela Lei ${ }^{\circ}$ 13.005 de 2014 (BRASIL, 2014) no sentido de induzir habilidades técnicas e políticas aos candidatos a diretores e integrar a participação das comunidades escolares ao processo, buscando superar as indicações políticas ainda vigentes nas redes de ensino (SOUZA, A., 2018), lastreadas no clientelismo, compadrio e patrimonialismo brasileiro.

O modelo de seleção de diretores adotado na rede municipal do Rio de Janeiro, do ponto de vista formal, apresenta como pressuposto que "a liderança positiva do gestor é preponderante na construção do sucesso escolar”. Dispõe que este gestor, nos três primeiros meses do mandato, “deverá coordenar o processo 
de construção de um projeto de gestão, em conjunto com a comunidade escolar, a ser aprovado pela Secretaria Municipal de Educação" (RIO DE JANEIRO, 2017, p. 56-57). De acordo com o documento orientador, as etapas realizadas na escola devem ter como ponto de partida a autoavaliação institucional com foco na "busca contínua pela garantia do acesso e do aprendizado do aluno" (MULTIRIO, 2018b).

Neste sentido, utilizamos o estudo de caso como método de pesquisa para analisar a percepção dos diretores escolares sobre as etapas de diagnose, autoavaliação, estabelecimento de metas e proposições, constitutivas do plano de gestão em duas escolas, a fim de compreender as concepções e os sentidos dos processos liderados por esses agentes públicos.

A discussão apresentada neste trabalho justifica-se dada a possível articulação do plano de gestão com os papéis exercidos pelos diretores na gestão pedagógica da escola e pela ação discricionária desses agentes implementadores que atuam na linha de frente da construção do plano de gestão. Lipsky (2010) caracteriza os atores que estão na linha de frente da entrega da política como burocratas do nível de rua, com importância fundamental na cadeia de implementação, pois (re)interpretam a política a partir de seus valores, conhecimentos, experiências, constrangimentos e contigências do Estado.

Para fins de organização, este trabalho está estruturado em seis seções, além desta introdução e das referências bibliográficas. A segunda seção apresenta uma revisão da literatura sobre o campo de políticas públicas. A terceira seção focaliza o desenvolvimento do campo de implementação no cenário internacional e o processo ainda em construção no país. A implementação do plano de gestão como mecanismo para aferir a competência técnica dos candidatos à direção de escola, no contexto da pós-burocracia, é discutida na quarta seção. A quinta seção apresenta o campo da pesquisa, as características das escolas e os perfis das diretoras selecionadas neste estudo analisa as formas como engendram a construção do plano e o sentido que atribuem a ele. Na sexta seção são apresentadas as considerações finais.

\section{Uma conversa preliminar sobre o campo de pesquisa em políticas públicas}

Nas últimas décadas, o campo de pesquisa em políticas públicas no Brasil ganha destaque como área de conhecimento e apresenta maior volume de pesquisas, notadamente após a promulgação da Constituição Federal de 
1988 e, posteriormente, no contexto da Reforma do Aparelho do Estado. Esses dois eventos alteraram substancialmente as políticas públicas no país. A Constituição de 1988 (BRASIL, 1988) se constituiu como um marco na ampliação da ação do Estado brasileiro na entrega de políticas focalizadas à população e institucionalização dos conselhos de controle social, desencadeando um movimento de descentralização da gestão pública na provisão dos serviços e incorporando a participação de novos atores nos processos decisórios. Nos anos de 1990, a reforma da máquina estatal impôs políticas restritivas de gastos, introduzindo os temas da eficiência e eficácia como atributos fundamentais para utilização de recursos públicos e alcance de resultados (SOUZA, C., 2006; HOCHMAN; ARRETCHE; MARQUES, 2007; FARAH, 2018).

A centralidade das políticas públicas favoreceu a organização mais consistente de um campo que se encontra em construção no país frente à produção estrangeira, com importante papel na tradução e compartilhamento de estudos internacionais em período mais recente. É nesse movimento que estudos nacionais passam a integrar abordagens analíticas de gerações consagradas de pesquisas no sentido de compreender a complexidade dos processos que envolvem desde a tomada de decisões governamentais até a entrega das políticas aos cidadãos. Essa dinâmica tem suscitado pesquisas orientadas para a policy analysis, na perspectiva de trazer à tona as razões pelas quais os governos escolhem determinadas políticas e de que forma as executam.

Do ponto de vista conceitual, são múltiplas as definições de políticas públicas e diversos são os autores que delimitaram o termo, no sentido de contribuir metodologicamente para compreendermos a ação do governo, a natureza e as dimensões do "processo técnico-político que visa definir e compatibilizar objetivos e meios entre atores sociais sujeitos a restrições" (HOWLETT; RAMESH; PERL, 2013, p. 6), que influenciam e produzem resultados sobre a vida de uma determinada população.

Para Jenkins (1978, p. 15, tradução nossa), política pública é o “conjunto de decisões inter-relacionadas, tomadas por um ator ou um conjunto de atores, que dizem respeito à seleção de metas e aos meios para alcançá-las, a partir de uma situação específica". A definição de Jenkins amplia o conceito de Dye (1972), que destaca o protagonismo dos governos nas escolhas feitas conscientemente para tomar decisões. Jenkins (1978) confere à política pública um caráter mais dinâmico e complexo, que envolve sua interação entre as estruturas do governo e os subsistemas político-administrativos. Neste sentido, além de avançar na caracterização, ajuda-nos a introduzir a importância das ideias, valores e conhecimentos na modelagem da política por aqueles que estão envolvidos na tomada de decisões e pelos atores que atuam e influenciam nos resultados. 
Grande parte da literatura sobre políticas públicas busca compreender as unidades que integram os seus processos. Dentre as abordagens utilizadas para análise das políticas, o ciclo de políticas se destaca como um recurso heurístico que tem o potencial de explicar didaticamente as características específicas e as inter-relações das etapas sequenciais que integram a política pública.

De acordo com Howlett, Ramesh e Perl (2013, p. 12-13), em linhas gerais, essa perspectiva analítica explicita metodologicamente as políticas públicas em quatro etapas: 1) agenda, 2) formulação, 3) implementação e 4) avaliação.

$\mathrm{Na}$ etapa da agenda, a literatura procura responder por que alguns problemas entram na agenda governamental e outros não merecem atenção do governo. Discute quais dinâmicas sociais levam os formuladores de políticas a inserir um determinado problema no conjunto de preocupações, transformando-o em política pública.

Segundo Kingdon (2006), na construção da agenda é necessário considerar as ideias e a influência dos grupos de pressão, bem como as circunstâncias que propiciam as condições ideais, ou as "janelas de oportunidade", para que determinadas soluções ascendam a agenda política.

A formulação se caracteriza pela tomada de decisão, elaboração de alternativas a serem adotadas no enfrentamento do problema, na definição dos objetivos e dos meios para alcançá-los. Essa fase constitui-se, como afirma Celina Souza (2006, p. 26), "no estágio em que os governos democráticos traduzem seus propósitos e plataformas eleitorais em programas e ações que produzirão resultados ou mudanças no mundo real". De acordo com a autora, nessa etapa ganha destaque o papel das eleições, das burocracias, dos partidos, das mídias e dos grupos de interesse.

Após a formulação é necessário colocar a política em prática. Esta é a fase da implementação, na qual os recursos são alocados e as regras são definidas para estruturar a política. De acordo com Lotta (2019, p. 13), esse "é o momento que depende fortemente da ação de burocratas e dos instrumentos de ação estatal".

As pesquisas que focalizam este campo de análise giram em torno da definição de variáveis que podem explicar o sucesso ou o fracasso da política, tais como: a falta de clareza dos objetivos, os diferentes estilos de implementação dos burocratas, a falta de controle dos subordinados e os frágeis contextos de cooperação nas instituições (MAZMANIAN; SABATIER, 1983).

Estudos mais recentes, como os de Lima e D’Ascenzi (2013), propõem a inclusão de dimensões cognitivas, ideias, valores e concepções de mundo dos atores. Os autores compreendem também que a interação entre as fases de formulação e implementação permite compreendê-las como processos contínuos, tornando possível explorar analiticamente as intenções contidas nos objetivos 
que estruturam a política e sua apropriação nos contextos locais pelos atores que a implementam.

Na etapa de avaliação são mensurados os resultados das ações empreendidas, no sentido de fornecer informações para os ajustes, a continuidade ou a descontinuidade da política. Busca-se avaliar as consequências previstas e não previstas e identificar as possibilidades de aperfeiçoamento da ação estatal. As pesquisas sobre avaliação geralmente utilizam técnicas quantitativas e qualitativas e podem focalizar tanto a avaliação dos processos quanto a avaliação dos impactos.

Nessa abordagem do ciclo de políticas as quatro etapas são dinâmicas e não seguem exatamente uma progressão linear, precisando ser compreendidas a partir das possíveis superposições, interações e interdependências entre elas. Entretanto, esse modelo sequencial tem como vantagem ser uma ferramenta de recorte do objeto de análise, que no caso deste estudo está situado na implementação.

\section{Implementação de políticas públicas: panorama geral e o campo da educação}

A construção do campo de pesquisas sobre implementação é um processo relativamente novo no Brasil. Durante as últimas décadas predominaram estudos acadêmicos que focalizaram a formulação e a avaliação das políticas (SOUZA, C., 2006). A literatura que aborda o estudo de implementação está ancorada principalmente em duas gerações analíticas que estruturaram o campo.

A primeira geração tem como base a perspectiva prescritiva e normativa, na qual prevalece a ideia de que o olhar sobre o processo de implementação deve partir das normas estabelecidas, ou seja, de cima para baixo. Essa abordagem, denominada top down, considera que a clareza dos objetivos e o controle sobre os atores que executam a política são as principais variáveis que explicam as falhas entre a formulação e a implementação.

A segunda geração, denominada bottom up, em contraste com a perspectiva "de cima para baixo", busca olhar a política "de baixo para cima", propondose a analisar a ação dos atores engajados na política, chamados por Lipsky (2010) de "street-level bureaucrats". De acordo com Lotta (2019), os estudos da atuação desses burocratas da linha de frente, ou burocratas do nível de rua, sobre a política, 
[...] reforçam a tese de que há muitos processos decisórios acontecendo na implementação, que a burocracia não é uma máquina ou peças de engrenagens, e que compreender como ela se comporta e como toma decisões é central às análises de políticas públicas (LOTTA, 2019, p. 16).

O burocrata do nível de rua foi identificado em estudo seminal de Lipsky (2010) como o implementador de política pública que entrega a política ao cidadão, fazendo a ponte entre o Estado e o usuário do serviço público. $\mathrm{O}$ autor cita como exemplos os policiais, enfermeiros, professores, médicos, assistentes sociais, entre outros. Na interação com os indivíduos, esses burocratas, que sofrem restrições, contingências e são constrangidos pelas normas impostas pelo Estado, atuam com margens de discricionariedade alterando as regras que estruturam a política.

Há também estudos sobre implementação que propõem observar a atuação da burocracia em outras dimensões, possibilitando análises sobre os burocratas de alto e de médio escalão, que recebem tais denominações de acordo com as posições e as relações hierárquicas estabelecidas na cadeia de implementação. Entre os burocratas de alto escalão, nomeadamente aqueles que desenham a política, destaca-se a burocracia federal que atua no processo de produção de políticas públicas e que maior autonomia para gerir recursos públicos (PIRES, 2012).

Os burocratas de médio escalão, ainda pouco analisados pela literatura, são aqueles que se encontram entre a elite política e os burocratas do nível de rua, muitas vezes atuando ambiguamente, com mais ou menos protagonismo e capacidade de realizar simultaneamente atividades técnicas e gerenciais no desempenho da gestão e direção intermediária (LOTTA; PIRES; OLIVEIRA, 2014; CAVALCANTE; LOTTA; YAMADA, 2018).

No Brasil, a agenda de estudos sobre implementação de políticas é uma construção ainda recente no campo da educação quando comparado aos outros campos de pesquisa, como o da saúde, por exemplo. Ainda são escassas as pesquisas que se apropriam desse referencial teórico para analisar a atuação de profissionais da educação nos contextos escolares ou em outras dimensões da política educacional. Contudo, ainda que seja observada a escassez de pesquisas, os diretores escolares receberam atenção em estudos recentes.

Temas relacionados ao desempenho dos alunos, clima escolar, liderança, e o papel do diretor foram explorados por Oliveira e Abrucio (2018) em pesquisa realizada em escolas da rede estadual de São Paulo. Nessa pesquisa os diretores escolares são definidos como burocratas de médio escalão, tendo como referência o contraste entre as características dos burocratas de nível de rua e de médio escalão construídas pelos autores num quadro comparativo. Em síntese, o quadro 
revela que os burocratas de médio escalão têm autonomia para gerir recursos públicos, lidam com as duas extremidades da hierarquia da burocracia pública e "sua atuação não é exclusivamente de atendimento do público-alvo, mas sim de coordenação e comando daqueles que implementam o serviço final", podendo ou não, ter contato direto com os cidadãos (OLIVEIRA; ABRUCIO, 2018, p. 213-214). A pesquisa revelou que os estilos de gestão afetam o resultado do desempenho dos alunos e que os diretores são peças-chave para articular formulação e implementação, mobilizando a capacidade de inovação e ações discricionárias, com foco na gestão organizacional.

O estudo de Ana Cristina Oliveira, Maria de Fátima Lima e Marina Oliveira (2018) analisou o papel dos diretores no processo de implementação de uma política de correção de fluxo na rede pública municipal do Rio de Janeiro. As autoras apontam que as atribuições e atividades desenvolvidas pelos diretores os conecta diretamente com os beneficiários ou público-alvo da política. Através de suas lógicas de ação, os diretores categorizam, julgam, selecionam e entregam a política com base em valores morais e ações discricionárias, alterando o escopo da política formulada no alto escalão e coordenada no nível intermediário da gestão. Neste sentido, o processo de investigação orientou a análise para a abordagem bottom up, contribuindo para que nesse estudo os diretores tenham sido categorizados como burocratas de nível de rua.

Os dois estudos são representativos do desafio encontrado na literatura para estabelecer, a priori, a definição da categoria na qual os diretores escolares estão inseridos na cadeia de implementação. Assim, os diretores podem ser definidos tanto como burocratas de médio escalão quanto de nível de rua, dependendo das atividades que desenvolvem no exercício da implementação da política analisada, da natureza da política e da particularidade do contexto organizacional da rede de ensino e da escola, que podem alterar a posição do diretor na cadeia de implementação.

Reconhecemos que os papéis desempenhados pelos diretores escolares são vastos e complexos, tornando muitas vezes ambíguas as suas atuações e posições na cadeia hierárquica de implementação nos contextos locais. Desta forma, a operacionalização da análise, a partir dos referenciais teórico-metodológicos consagrados na Ciência Política e da empiria, deve ser construída considerando essas particularidades, a fim de que a definição conceitual do diretor como burocrata de nível de rua ou de médio escalão não parta de pressuposições, mas da atuação desses atores sobre/na política. Neste estudo, a perspectiva é analisar o plano de gestão como ação integrada à política de seleção de diretores escolares, na perspectiva do planejamento da gestão escolar e da gestão democrática. De acordo com a Resolução n $^{\circ} 20$ de 29 de setembro de 2017 (RIO DE JANEIRO, 2017), que regulamentou o último processo de seleção de diretores na rede, a elaboração 
do plano de gestão deve ocorrer no primeiro trimestre do ano letivo, após a homologação do resultado e a posse do diretor, sob a supervisão da Secretaria Municipal de Educação (SME) e com a participação da comunidade escolar.

\section{Seleção de diretores, plano de gestão e o planejamento escolar no contexto da pós-burocracia}

Nas redes públicas de ensino do Brasil o diretor escolar é geralmente um funcionário público, vinculado à União, Estado ou Município, investido em uma função pública para fazer a interlocução entre o Estado e a escola, exercendo, portanto, um duplo papel: de representante da administração pública do Estado e da comunidade escolar (SOUZA, A., 2006; OLIVEIRA, A.; LIMA; OLIVEIRA, M., 2018).

O acesso ao cargo e provimento do diretor se constituiu historicamente através de quatro mecanismos, ainda vigentes nos entes federativos: indicação (precedida ou não de lista tríplice), concurso público, eleição ou consulta (integrando voto direto da comunidade escolar) e modalidades mistas ou híbridas (incorporando critérios técnicos e participação da comunidade escolar).

A livre indicação política de diretores escolares pelos poderes públicos locais, sem legitimação da comunidade escolar ou exigência de qualificação técnica, foi frequente até os anos de 1980, em consonância com o patrimonialismo e o clientelismo que orientavam a ocupação de cargos públicos na máquina estatal. Em contraposição à indicação política, o concurso público para seleção de diretores passou a ser adotado em redes públicas do país, simultaneamente às indicações, englobando provas e apresentação de títulos, no sentido de resguardar princípios weberianos como a impessoalidade e a competência técnica no processo de escolha do diretor. Contudo, o concurso não traduzia a demanda por participação arraigada nos movimentos pela redemocratização do país e defesa da gestão democrática dos anos de 1980. Naquele contexto, o campo da educação apresentava como pauta a eleição direta de diretores, com participação local manifestada pelo voto direto das comunidades escolares, no sentido de superar a influência de agentes políticos na nomeação dessas lideranças escolares.

Nos anos de 1990, durante a reforma do aparelho administrativo do Estado e expansão do paradigma pós-burocrático de matriz gerencial, o processo de descentralização da gestão educacional e escolar e, simultaneamente, a demanda pela produção de resultados, eficiência administrativa e eficácia escolar, aliada 
aos objetivos estratégicos com foco na análise e uso de indicadores, orientaram a instituição de mecanismos de seleção de diretores escolares mais complexos. Tais mecanismos incorporaram requisitos técnicos, dispostos como critérios nas normas que regulamentavam os processos seletivos de diretores escolares, no sentido de definir um perfil de gestor que respondesse aos novos desafios político-pedagógicos relacionados à organização de planejamentos estratégicos orientados para accountability.

A reforma administrativa pós-burocrática de matriz gerencial tem como referência a "Nova Gestão Pública", implementada nos anos de 1980 pelos Governos de Ronald Reagan, nos Estados Unidos e de Margareth Thatcher, na Inglaterra. Este paradigma de gestão postulava que a ineficiência da administração pública poderia ser superada com a redução do Estado de Bem-Estar Social e a incorporação de princípios, ferramentas e práticas do setor privado na máquina pública. Nesse sentido, o estabelecimento de parcerias público-privadas, a produtividade, a competitividade, a utilização de indicadores, a centralidade da avaliação, a responsabilização pelos resultados com publicização e prestação de contas, foram apresentados como pressupostos para o alcance da eficiência e da eficácia da gestão.

No Brasil, o paradigma pós-burocrático gerencial se materializa fortemente a partir da implantação do Plano Diretor de Reforma do Aparelho do Estado por Bresser Pereira, Ministro da Reforma do Estado, entre os anos de 19951999. De acordo com Lima (2014, p. 2), observa-se a partir desse período a evolução progressiva de formas mistas ou híbridas de seleção e de provimento de diretores nas redes públicas de ensino no país “com o propósito de compatibilizar mecanismos participativos, enraizados na gestão democrática, com as habilidades técnicas necessárias ao desempenho ocupacional do diretor". Contudo, em razão da autonomia, multiplicidade, bem como das diversas composições de forças políticas e distintos interesses dos Executivos e Legislativos dos entes federados, a aferição da capacidade técnica dos diretores se apresenta a partir de instrumentos particulares, tais como: certificação, currículo, prova, apresentação de plano/projeto de gestão previamente ou posteriormente à eleição, associados à participação da comunidade escolar, etapa integrante desse processo.

No contexto atual, a institucionalização desse mecanismo de seleção de diretores se efetivou nacionalmente através da Lei 13.005, de 2014 (BRASIL, 2014), que aprova o Plano Nacional de Educação, na medida em que essa Lei determina que as redes públicas de ensino considerem, conjuntamente, para a nomeação dos diretores de escola, critérios técnicos de mérito e desempenho e participação da comunidade escolar, observando os princípios da gestão democrática. 
Em relação à rede pública municipal do Rio de Janeiro, campo deste estudo, o último processo de seleção de diretores, ocorrido em 2017, para o trienio 2018-2020, foi regulamentado por meio da Resolução $n^{0} 20$, de 29 de setembro de 2017 (RIO DE JANEIRO, 2017). Conforme disposto na Resolução, dentre os princípios que orientam a seleção dos diretores pode-se destacar: a liderança positiva do gestor para construção do sucesso escolar; a consolidação do processo de democratização da escola com integração constante entre escola, família e comunidade; e gestão democrática e participativa. $\mathrm{O}$ instrumento legal estabelece, ainda, que a construção do plano de gestão deve ocorrer após a posse dos diretores, sob a supervisão corresponsável da SME e com a participação da comunidade escolar (RIO DE JANEIRO, 2017).

Nota-se que o texto legal não menciona os procedimentos relativos à construção do plano de gestão e a definição dos papéis dos diretores nas etapas que integram o processo. Tais informações foram divulgadas após a posse dos diretores, por meio da Campanha de Autoavaliação das Unidades Escolares e do anúncio do Kit de Autoavaliação em comunicados internos e meios digitais da SME, como o site da MultiRio - Empresa Municipal de Multimeios da Prefeitura da Cidade do Rio de Janeiro.

De acordo com informações divulgadas no site, o Kit de Autoavaliação apresenta "sugestões e orientações que visam garantir a construção de um diagnóstico que ilumine a missão e favoreça a construção do plano de gestão em cada escola da Rede" (MULTIRIO, 2018a). O diagnóstico orienta a autoavaliação coletiva que "deve estar pautada na razão de ser das unidades: a busca contínua pela garantia do acesso e aprendizado do aluno" (MULTIRIO, 2018a). Os textos indicam que os diretores são convocados a coordenar o processo de autoavaliação, a promover e conduzir as reuniões com representantes dos segmentos da comunidade escolar, a registrar as decisões e elaborar o texto final, no sentido de construir "uma gestão, ao mesmo tempo, democrática e eficaz" (MULTIRIO, 2018a). Nesse sentido, os diretores são figuras centrais no processo de implementação do plano de gestão, que na escola tem início com o diagnóstico realizado em conjunto com a comunidade escolar, sob a liderança do diretor, com apoio de um supervisor administrativo e um supervisor pedagógico (MULTIRIO, 2018a, 2018b).

Em relação às formas de mediação, aos papéis exercidos e à atuação dos agentes do alto escalão (Secretaria Municipal de Educação - SME) e do médio escalão (Coordenadorias Regionais de Educação-CREs), o site oferece poucas informações, limitando-se à mencionar brevemente a sequência das ações constituintes do processo. De acordo com o calendário, as 11 Coordenadorias Regionais de Educação promoveram um curso de formação em gestão pedagógica e administrativa para os diretores empossados em janeiro. Posteriormente, para 
apoiá-los na elaboração do diagnóstico da gestão, os diretores contaram com dois supervisores: um pedagógico e outro administrativo, auxiliando-os a realizar na escola, no período de abril e maio, o levantamento "dos pontos fortes, que estão dando certo, como aqueles que precisam ser corrigidos" (MULTIRIO, 2018a). De acordo com o material que orienta o processo de autoavaliação nas escolas, o Plano de Gestão deve ser estruturado em três seções: 1. A escola que somos, contendo o diagnóstico e a autoavaliação da escola; 2. A escola que queremos ser, apresentando a identidade construída pela unidade escolar, as metas e resultados desejados, e 3. Como vamos chegar lá, contendo estratégias e propostas elaboradas pela comunidade escolar para alcançar os resultados. O texto informa ainda que o "Plano de Gestão, validado pelo nível central, será a base para o acompanhamento do trabalho desenvolvido pela unidade escolar ao longo de todo o ano" (MULTIRIO, 2018b).

Neste estudo focalizamos a análise das etapas correspondentes ao diagnóstico, autoavaliação e registro final do plano, considerando a atuação dos diretores na escola a partir de suas percepções, particularmente sobre a caracterização do plano de gestão, a relação estabelecida com as comunidades escolares, com os agentes das coordenadorias e da SME envolvidos no processo. A intenção inicial era analisar a percepção dos diretores sobre a implantação do plano de gestão, após as etapas ocorridas precedentemente na escola relacionadas ao diagnóstico, autoavaliação e encaminhamento do texto final do plano pela direção à SME, para análise, avaliação e considerções. O início da implementação era prevista para ocorrer no segundo semestre de 2018. Contudo, essa etapa foi adiada, sem previsão de continuidade do processo, em virtude da exoneração do Secretário de Educação em julho de 2018.

\section{O campo da pesquisa: escolas e diretoras}

A entrada no campo de pesquisa inicia-se entre os meses de setembro e outubro de 2018, por meio da visita às duas escolas de ensino fundamental da rede pública municipal do Rio de Janeiro, conforme critérios estabelecidos, explicitados a seguir.

A rede pública municipal do Rio de Janeiro, considerada a maior rede municipal de ensino da América Latina, era composta na ocasião da pesquisa, de acordo com o site oficial da SME, por 1.539 unidades escolares, integradas às 11 Coordenadorias Regionais de Educação, conforme as áreas de abrangência. Este órgão, intermediário da gestão educacional, articula as políticas entre o nível macro da gestão (SME) e as escolas. No ano de 2018, conforme dados 
do Censo Escolar, a rede municipal atendia a 146.556 matrículas na Educação Infantil, a 471.361 no Ensino Fundamental, 26.097 na Educação de Jovens e Adultos e a 15.987 na Educação Especial.

Em termos metodológicos, como relatado, foi realizada previamente pesquisa bibliográfica e análise de documentos oficiais em formato eletrônico, constituídos como fontes primárias, referentes às leis municipais, portarias, resoluções, instruções normativas e informações oficiais sobre a seleção, provimento de diretores e o plano de gestão, através dos portais eletrônicos da SME.

Posteriormente foram realizadas entrevistas semiestruturadas com diretoras de duas escolas. As diretoras foram selecionadas a partir de critérios pré-definidos que compatibilizaram caracterísiticas das escolas nas quais exerciam o mandato, e os perfis profissionais. Em relação às escolas, foram selecionadas e pareadas escolas integrantes de Coordenadorias Regionais de Educação (CREs) localizadas em pontos diferentes da cidade, que atendiam na ocasião da pesquisa aos anos finais do ensino fundamental, com o total de 600 a 800 alunos matriculados, localizadas na faixa 3 ou 4 do nível sócio-econômico (NSE) médio ${ }^{1}$.

Como filtros para seleção das diretoras foram considerados e contrastados o tempo de exercício na rede de ensino e o tempo de experiência na gestão escolar, de tal modo que entre as diretoras selecionadas uma tivesse maior tempo de exercício e de experiência em contraste com a segunda, com menos tempo de exercício na rede e com experiência recente na gestão.

$\mathrm{Na}$ ocasião foram realizadas três visitas a cada uma das escolas, no intuito de buscar informações sobre os perfis sociodemográficos da diretoras, compreender quais eram as suas percepções sobre o plano de gestão, o processo de diagnóstico e autoavaliação, o seu papel e dos demais agentes envolvidos no processo, privilegiando as perspectivas de democratização da escola, as metas e proposições estabelecidas.

Para fins de organização dos dados, o quadro 1 sintetiza as informações sobre as escolas, denominadas doravante de Escola A e Escola B. Além dos dados relativos ao total de matrículas e NSE, coletados no Instituto Nacional de Estudos e Pesquisas Educacionais Anísio Teixeira/Ministério da Educação (INEP/MEC), foram adicionadas as informações sobre desempenho dos alunos, considerando que essa dimensão da escola é focalizada na etapa do diagnóstico. Também foram adicionadas as informações obtidas nas entrevistas sobre o andamento do projeto político pedagógico, levando em conta que esse

1 A intenção inicial era selecionar duas escolas com as mesmas faixas de NSE (faixa 3 ou 4), a partir do Indicador de Nível Socioeconômico das Escolas da Educação Básica (INSE), desenvolvido pelo MEC/INEP. Contudo, não foi possível compatibilizar todos os critérios. Sendo, por isso, selecionadas duas escolas com faixas próximos de NSE médio, porém diferentes. 
instrumento de planejamento participativo, desenvolvido sob a liderança da equipe gestora, pode ser considerado uma proxy da relação entre a organização da escola e a gestão democrática estabelecida pelo diretor. Pode-se ainda supor que esse instrumento se constituíria como um apoio durante as reuniões para elaboração do plano de gestão.

QUADRO 1 - CARACTERÍSTICAS DAS ESCOLAS

\begin{tabular}{|c|c|c|}
\hline CARACTERÍSTICAS & ESCOLAA & ESCOLA B \\
\hline CRE & $8^{\text {a }}$ & $7^{\text {a }}$ \\
\hline TOTAL DE MATRÍCULAS & 645 & 798 \\
\hline NSE DOS ALUNOS & 4 & 3 \\
\hline PROJETO POLÍTICO PEDAGÓGICO & CONCLUÍDO & EM CONSTRUÇÃO \\
\hline IDEB - ANOS FINAIS DO EF (2017) & 5,2 & 4,8 \\
\hline
\end{tabular}

FONTE: INEP/MEC e informações coletadas nas entrevistas semiestruturadas

A entrada nas escolas para realização das entrevistas ocorreu no segundo semestre de 2018, ocasião na qual os diretores deveriam iniciar a implementação do plano de gestão, previamente avaliado pela SME, como relatado. Contudo, a devolução dos registros às escolas havia sido adiada em virtude da exoneração do Secretário de Municipal de Educação, em julho de 2018.

De acordo com o exposto no quadro 2, as duas escolas são dirigidas por mulheres brancas, na faixa etária de 30 a 50 anos, que cursaram pós-graduação nas áreas de formação inicial.

QUADRO 2 - PERFIS DAS DIRETORAS

\begin{tabular}{|c|c|c|}
\hline PERFIS DAS DIRETORAS & $\begin{array}{c}\text { DIRETORA DA } \\
\text { ESCOLA A }\end{array}$ & $\begin{array}{c}\text { DIRETORA DA } \\
\text { ESCOLA B }\end{array}$ \\
\hline COR/RAÇA AUTODECLARADA & BRANCA & BRANCA \\
\hline FAIXA ETÁRIA & 40 A 50 ANOS & 30 A 40 ANOS \\
\hline FORMAÇÃO - NÍVEL MAIS ALTO & $\begin{array}{c}\text { PÓS-GRADUAÇÃO } \\
\text { EM EDUCAÇÃO }\end{array}$ & $\begin{array}{c}\text { PÓS-GRADUAÇÃO } \\
\text { EM HISTÓRIA }\end{array}$ \\
\hline TEMPO DE EXERCÍCIO NA REDE & 23 ANOS & 6 ANOS \\
\hline TEMPO DE EXERCÍCIO NA GESTÃO & 16 ANOS & 1 ANO \\
\hline
\end{tabular}

FONTE: INEP/MEC e informações coletadas nas entrevistas semiestruturadas 
Por intermédio das entrevistas foi possível verificar que as diretoras das duas escolas têm trajetórias profissionais e acadêmicas distintas, mas sempre trabalharam no campo da educação. A diretora da Escola A é professora concursada do municípo do Rio de Janeiro há 23 anos para lecionar nos anos iniciais do ensino fundamental. Foi professora regente de turma, exerceu a função de Coordenadora Pedagógica durante 4 anos em outra escola da rede e no decorrer de 3 anos na escola na qual exerce o $3^{\circ}$ mandato de diretora. Cursou Pedagogia e concluiu pós-graduação nas áreas de Supervisão, Orientação Educacional e Psicopedagogia. Atuou como diretora conselheira do Conselho de Diretores da $8^{\mathrm{a}}$ CRE durante dois anos. Considera que os diretores são as lideranças que devem conduzir a gestão "prioritariamente a favor da permanência, da aprendizagem e da melhoria do desempenho dos alunos". Lembrou que sua formação e trajetória contribuíram para desenvolver mudanças na escola.

Entrei aqui como Coordenadora Pedagógica com um escola com nivel de reprovação alto, fomos fazendo um trabalho gradual, um trabalho com os professores, um trabalho de estudo [...] como diretora não esqueço nunca desse meu lado pedagógico.

A diretora da Escola B é professora de História, concursada há 6 anos para lecionar nos anos finais do ensino fundamental. Antes de ingressar na rede municipal do Rio de Janeiro foi oficial militar durante 4 anos, atuando na área da educação, com foco na História Militar. Após esse período prestou concurso e exerceu durante 4 anos a função de professora regente em outra escola da rede, até ser convidada pela CRE para atuar como interventora de uma unidade escolar que precisava passar por mudanças. Segundo relatou, o convite foi mediado pelo diretor da escola na qual trabalhava, pois reconheceu nela condições de intervir e imprimir mudanças numa escola que naquele momento "enfrentava a exoneração da equipe gestora, apresentava episódios diários de violência entre alunos e queixas frequentes da vizinhança". Reconhece que o ethos militar, ainda impregnado nas suas ações, pode ter contribuído para o convite.

Se você me visse com roupa de civil... Eu- tinha cara de militar, eu andava de coque. Porque onde eu trabalhava, quando eu era militar, eu era a única mulher. Então, assim, você fica uma pessoa muito séria no lidar. 
As entrevistas revelaram que elementos vinculados aos perfis das diretoras parecem influenciar a relação com os supervisores e as comunidades escolares, a concepção do plano de gestão, o distanciamento ou aproximação das normas na condução do processo e as propostas apresentadas para atingir as metas estabelecidas. A seguir, destacamos esses pontos, observando o protagonismo das diretoras que apresentam distintas interpretações sobre os processos de elaboração e as prioridades que devem estar contidas no plano de gestão.

\section{O plano de gestão na percepção das diretoras}

As etapas de diagnóstico e autoavaliação contaram com dois supervisores, encaminhados pelas CREs às escolas. No tocante ao papel desses atores, na percepção da diretora da Escola A, "a atribuição deles é nos ajudar, e ajudar a essa escola a não fracassarno pedagógico ou no administrativo. O supervisor também está contribuindo para isso". Nesse sentido, seriam corresponsáveis pelo processo. No entanto, atribuiu papel secundário, quase inexpressivo, a esses agentes, pois os supervisores, segundo afirmou, "somente observaram o que a escola estava fazendo e algumas vezes levaram as propostas que elaboramos como sugestões para apresentar às outras escolas". A diretora da Escola B tem uma percepção mais hierarquizada e de diálogo mais "produtivo" com os supervisores, especialmente o pedagógico, com quem a escola manteve contato mais permanente, conforme deixou transparecer:

Se você está discutindo ideias, se você está falando sobre pessoas, então a gente senta, olha tabela de resultados e discute o que a gente pode melhorar, o que é essencial, o que não é. E ai, assim, eu tenho a visão da escola e ele tem a visão da CRE.

Distintamente do "melindre" observado em alguns diretores, devido a preseça dos supervisores nas escolas, compreende que

existe uma hierarquia de comando e você segue, e você tem que escutar. Então você aprende a lidar com essa questão da supervisão. Alguém que está observando, que está falando, que está, né: - Oh, isso aqui não é assim... 
As distintas percepções e relações estabelecidas entre as diretoras e os agentes responsáveis pela supervisão do diagnóstico e da autoavaliação da escola, etapas consitutivas do plano de gestão, deixam transparecer, como afirmado por Lima e D'Ascenzi (2013), que apropriação das diretrizes e normas são modeladas conforme os valores, experiências e dimensões cognitivas dos agentes implementadores nos contextos locais.

De acordo com a Resolução que dispõe sobre a seleção dos diretores, o diretor ocupante do cargo "coordenará o processo de construção de um projeto de gestão, em conjunto com a comunidade escolar, que será implementado no primeiro ano de gestão". Essa orientação está em consonância com o princípio da gestão democrática e parece também ter o intuito de promover a integração constante entre escola, família e comunidade, conforme disposto nas diretrizes e orientações da SME. O texto do Kit de Autoavaliação enfatiza a participação da comunidade escolar, e, para tanto, orienta a organização de reuniões por segmentos para a realização do diagnóstico e da autoavaliação, com uso de ferramentas e metodologias sugeridas. Segundo a diretora da Escola A, as reuniões aconteceram com a presença dos professores e representantes da comunidade escolar- do Conselho Escola Comunidade (CEC). Para ela " $o$ papel do CEC é estar junto a direção para fazer com que a escola, ela... se desenvolva no pedagógico, no administrativo...". Na Escola B, as reuniões contaram exclusivamente com a participação dos professores. A diretora percebe que as famílias são muito afastadas do ambiente escolar e têm dificuldades para se deslocar até a escola, conforme narrou. "O problema é a comunidade vir à escola. É muito dificil. Porque a comunidade mora longe da escola e existe um custo pra eles virem pra cá.". Indagada sobre a organização e funcionamento do CEC, respondeu: "Ah, o CEC? Isso ainda é um processo em construção".

Sobre a caracterização do plano de gestão, a diretora da Escola A considera que, ainda que tenham sido apresentadas ferramentas para a realização de um plano estratégico, o plano de gestão

tem semelhança com a construção do Projeto Político Pedagógico. Você enxerga ali a escola que somos, a escola que... não, a escola que éramos, a que somos e a que queremos ser, só que com outras palavras.

Compreende que "o plano de gestão irá orientar o plano de ação do diretor". Neste sentido, organizou as reuniões ressaltando "a visão, os valores e a missão da escola". Segundo narrou, o plano de gestão focalizou as questões relacionadas à melhoria da aprendizagem, ao reforço escolar e à redução da 
distorção idade-série. "Aqui o foco é o aluno e a aprendizagem do aluno". Para a diretora da Escola B o Plano de Gestão é "baseado no diálogo. É muito dialógico. Assim: eu falo, eu te escuto, eu repenso, pra que a gente possa chegar a um um pacto de funcionamento". Afirma que o pacto tem como objetivo "reconstruir o orgulho de fazer parte daqui e não a vergonha de fazer parte dessa escola, de uma escola mal falada".

Finalmente, sobre as metas e as propostas apresentadas no plano de gestão, a diretora da Escola A definiu em poucas palavras o resultado do processo coordenado na escola.

A proposta da escola é ensinar e o aluno aprender. Não existe maquiagem, não existe nada. A supervisora que me acompanhou desde o início do ano viu a nossa recuperação paralela, ela começa a partir do primeiro dia de aula.

Informou que nas reuniões foram analisados os indicadores de desempenho e fluxo, bem como a atuação dos organismos de participação. Assim, relata que "a proposta é melhorar o desempenho dos alunos, desenvolvendo projetos de recuperação de aprendizagem para reduzir os conceitos insuficientes. $O$ fortalecimento das representatividades é importante para alcançar essas metas". A diretora da Escola B narrou que o plano de gestão focalizou a ordem, a disciplina, o engajamento, o bem-estar dos alunos e professores. Relatou que recuperou o hino da escola, esquecido pela comunidade escolar, e estabeleceu como prioridade o sentimento de pertencimento:

Em três anos, ou eu trabalho o pertencimento, o orgulho de fazer parte da escola, ou eu trabalho o resultado. [...] A escola tem um hino. Então, hoje os alunos cantam o hino da escola. Eles cantaram na formatura. Antes era impensável!

Assim como no estudo de Ana Cristina Oliveira, Maria de Fátima Lima e Marina Oliveira (2018), as diretoas das escolas pesquisadas, conectadas diretamente aos representantes das comunidades escolares que participaram da diagnose e da autoavaliação das escolas, etapas preliminares e constitutivas da implementação do plano de gestão, apresentaram percepções diferentes do processo. A partir das suas experiências profissionais, valores e julgamentos, 
alteraram com margens de liberdade os procedimentos e operacionalizaram diversamente os processos de regulação externa, podendo modificar os resultados previstos e o objetivo da política.

\section{Considerações finais}

O trabalho traz à tona as distintas percepções e reações das diretoras sobre as etapas que envolveram a elaboração do plano de gestão implementadas por essas lideranças escolares. A relação com as comunidades escolares, com os surpervisores das CREs e a condução diferente dos processos parecem estar associadas à formação, valores e experiências. Nota-se que prevaleceu entre as diretoras a liberdade de ação e, portanto, a discricionariedade para definir as prioridades da gestão escolar, inclusive o uso/não uso de indicadores educacionais, numa perspectiva bottom up.

É importante destacar que é na administração das redes públicas de ensino e das escolas, ou seja, nas estruturas formais do setor público, em contato com os cidadãos, que as políticas e programas educacionais são implementados efetivamente. Assim, os diretores são as pessoas que nos contextos locais fazem o nexo políticas-cidadãos e que podem potencializar os processos participativos no âmbito da educação. Portanto, ainda que não sejam os exclusivos responsáveis pelo êxito escolar, os diretores têm importante papel no diagnóstico, no planejamento e na gestão das políticas públicas, frente aos novos desafios educacionais.

Neste trabalho observamos que as ações das diretoras, orientadas pelo plano de gestão, podem não corresponder à solução de problemas que envolvam a redução das desigualdades educacionais e escolares. Desta forma, a pesquisa busca contribuir para ampliar os estudos sobre implementação, a partir da análise da atuação de profissionais da educação nos contextos escolares ou em outras dimensões da política educacional, no sentido de compreender as restrições, constrangimentos e ações discricionárias que influenciam na entrega da política aos cidadãos. 


\section{REFERÊNCIAS}

BRASIL. [Constituição (1988)]. Constituição da República Federativa do Brasil. Brasília, 1988. Brasília, DF: Presidência da República, [2020]. Disponível em: http:// www.planalto.gov.br/ccivil_03/constituicao/constituicaocompilado.htm. Acesso em: 30 set. 2020.

BRASIL. Presidência da República. Lei Federal 13.005, de 25 de junho de 2014. Aprova o Plano Nacional de Educação - PNE e dá outras providências. Brasília, DF: Presidência da República, 2014. Disponível em: http://www.planalto.gov.br/ccivil_03/_ato20112014/2014/lei/113005.htm. Acesso em: 3 set. 2020.

CAVALCANTE, Pedro Luiz; LOTTA, Gabriela; YAMADA, Erika Mayumi. O desempenho dos burocratas de médio escalão: determinantes do relacionamento e das suas atividades Caderno EBAPE, Rio de Janeiro, v. 16, n. 1, p. 14-34, jan./mar. 2018. Disponível em: https://doi.org/10.1590/1679-395167309. Acesso em: 6 out. 2020.

DYE, Thomas. Understanding public policy. Englewood Cliffs: Prentice-Hall, 1972.

FARAH, Marta Ferreira Santos. Abordagens teóricas no campo de política pública no Brasil e no exterior: do fato à complexidade. Revista do Serviço Público, Brasília, n. 69, p. 53 - 84, 2018. Disponível em: https://doi.org/10.21874/rsp.v69i0.3583. Acesso em: 2 set. 2020.

HOCHMAN, Gilberto; ARRETCHE Marta; MARQUES, Eduardo (org.). Politicas Públicas no Brasil. Rio de Janeiro: Editora FIOCRUZ, 2007.

HOWLETT, Michael; RAMESH, M.; PERL, Anthony. Política pública: seus ciclos e subsistemas: uma abordagem integral. Rio de Janeiro: Elsevier, 2013.

JENKINS, Willian. Policy Analysis: a Political and Organizational Perspective. Londres: Martin Robertson, 1978.

KINGDON, John. Como chega a hora de uma ideia? In: SARAIVA, Enrique; FERRAREZI, Elisabete (org.). Coletânea de políticas públicas: introdução à teoria da política pública. Brasília: ENAP, 2006. v. 1, p. 219-224.

LIMA, Luciana Leite; D'ASCENZI, Luciano. Implementação de políticas públicas: perspectivas analíticas. Revista de Sociologia e Política, Curitiba, v. 21, n. 48, p. 101110, dez. 2013. Disponível em: https://doi.org/10.1590/S0104-44782013000400006. Acesso em: 20 out. 2020.

LIMA, Maria de Fátima Magalhães. Modalidades de escolha e de provimento de diretores escolares: desafios e alternativas para a gestão democrática e o alcance da qualidade da educação. In: CONGRESSO IBERO AMERICANO DE POLÍTICA E ADMINISTRAÇÃO DA EDUCAÇÃO. POLÍTICAS E PRÁTICAS DE ADMINISTRAÇÃO E AVALIAÇÃO DA EDUCAÇÃO IBERO-AMERICANA, 4., 2014, Porto, Portugal. Anais [...]. Porto: ANPAE, 2014. CD-ROM. 
LIPSKY, Michael. Street-level bureaucracy: dilemmas of the individual in public service. New York: Russell Sage Foundation, 2010.

LOTTA, Gabriela. A política pública como ela é: contribuições dos estudos sobre implementação para a análise de políticas públicas. In: LOTTA, Gabriela (org.). Teoria e análises sobre implantação de políticas públicas no Brasil. Brasília: ENAP, 2019. p. 11-38.

LOTTA, Gabriella; PIRES, Roberto; OLIVEIRA, Vanessa. Burocratas de médio escalão: novos olhares sobre velhos atores da produção de políticas públicas. Revista do Serviço Público, Brasília, n. 65, p. 463-492, out./dez. 2014. Disponível em: https:// doi.org/10.21874/rsp.v65i4.562. Acesso em: 06 out. 2020.

MULTIRIO. Gestão escolar: as novas diretrizes da SME. Rio de Janeiro, 2018a. Disponível em: http://www.multirio.rj.gov.br/index.php/leia/reportagens-artigos/ reportagens/13521-gest $\% \mathrm{C} 3 \% \mathrm{~A} 30$-escolar-as-novas-diretrizes-da-sme. Acesso em: 15 out. 2020 .

MULTIRIO. Kit de Autoavaliação das Unidades Escolares. Contextualiza o processo de autoavaliação escolar, sugere metodologias e ferramentas e explica como o Plano de Gestão deve ser estruturado. Rio de Janeiro, 2018b. Disponível em: http://www.multirio. rj.gov.br/index.php/leia/publicacoes/kits/13761-kit-de autoavalia\%C3\%A7\%C3\%A3odas-unidades-escolares. Acesso em: 15 out. 2020.

OLIVEIRA, Vanessa Elias; ABRUCIO, Fernando Luiz. Burocracia de médio escalão e diretores de escola: um novo olhar sobre o conceito. In: PIRES, Roberto; LOTTA, Gabriela; OLIVEIRA, Vanessa Elias (org.). Burocracia e políticas públicas no Brasil: interseções analíticas. Brasília: IPEA: ENAP, 2018. p. 207-226.

OLIVEIRA, Ana Cristina Prado; LIMA, Maria de Fátima Magalhães; OLIVEIRA, Marina Meira. O diretor escolar enquanto agente implementador das políticas públicas educacionais. In: FERREIRA, Antônio Gomes; BERNARDO, Elisangela da Silva; MENEZES, Janaína Specht da Silva (org.). Políticas e gestão em educação em tempo integral: desafios contemporâneos. Curitiba: CRV, 2018. p. 339-364.

PIRES, Roberto. Burocracias, gerentes e suas "histórias de implementação": narrativas do sucesso e fracasso de programas federais. In: FARIA, Carlos Aurélio (org.). Implementação de políticas públicas: teoria e prática. Belo Horizonte: Editora PUC Minas, 2012. p. 182-220.

RIO DE JANEIRO (Município). Secretaria Municipal de Educação. Resolução nº 20, de 29 de setembro de 2017. Dispõe sobre o processo de Seleção de Gestores das Unidades Escolares da Rede Pública do Sistema Municipal de Ensino da Cidade do RJ e dá outras providências. Diário Oficial do Município: Seção 1, Rio de Janeiro, Ano XXI, n. 136, p. 56-57, 2 out. 2017.

SABATIER, Paul; MAZMANIAN, Daniel. La implementación de la política pública: um marco de análisis. In: VARELLA, Luis F. Aguilar. La implementación de las políticas. México: Miguel Ángel Porrua, 1983. p. 323-372. 
SOUZA, Ângelo Ricardo. O perfil da gestão escolar no Brasil. 2006. 333 f. Tese (Doutorado em Educação) - Pontifícia Universidade Católica de São Paulo, São Paulo, 2006.

SOUZA, Ângelo Ricardo. A gestão democrática da escola pública no Brasil: o que mudou entre 2003 e 2015? In: CARVALHO, Cynthia Paes de; OLIVEIRA, Ana Crista Prado; CANEDO, Maria Luiza (org.). Gestão escolar e qualidade da educação: caminhos e horizontes de pesquisa. Curitiba: CRV, 2018. p. 213-323.

SOUZA, Celina. Políticas Públicas: uma revisão da literatura. Sociologias, Porto Alegre, ano 8, n. 16, p. 20-45, 2006. (Dossiê - Políticas públicas: uma revisão da literatura). Disponível em: https://doi.org/10.1590/S1517-45222006000200003. Acesso em: 06 ago. 2020.

SOUZA, Celina. Estado da Arte da pesquisa em políticas públicas. In: HOCHMAN, Gilberto; ARRETCHE Marta, MARQUES, Eduardo (org.). Políticas públicas no Brasil. Rio de Janeiro: Editora FIOCRUZ, 2007. p. 65-86.

Texto recebido em 06/12/2020.

Texto aprovado em 16/04/2021. 